\title{
Energy Transduction in Chlorobium limicola: Role of Membrane-bound Adenosine Triphosphatase and the Proton Electrochemical Gradient
}

\author{
By ALAN SISSONS AND MELVIN MIDGLEY* \\ Department of Biochemistry, University of Hull, Hull HU6 $7 R X$
}

(Received 6 August 1980)

\begin{abstract}
Photophosphorylation in vivo by Chlorobium limicola was inhibited by lipophilic cations and the energy-transfer inhibitors diphenylphosphorylazide, Dio-9, 4-chloro-7-nitrobenzofurazan and chlorhexidene. Membrane-bound ATPase activity was also inhibited by these energytransfer inhibitors. The formation of a membrane potential was stimulated approximately 1.7 -fold on illumination, rising to a value between -110 and $-150 \mathrm{mV}$. The sensitivity of the processes producing this membrane potential to uncouplers, energy-transfer inhibitors and 2-heptyl-4-hydroxyquinoline- $N$-oxide was measured in the light and the dark.
\end{abstract}

\section{INTRODUCTION}

In a previous investigation of photophosphorylation in Chlorobiaceae (Burns \& Midgley, 1976) it was shown that an ATPase was associated with the cytoplasmic membrane of Chlorobium limicola f.sp. thiosulphatophilum. This ATPase was sensitive to inhibitors such as carbodiimides and phloridzin. Photophosphorylation, when measured in vivo, was also sensitive to these inhibitors suggesting that the ATPase was involved in this process. It has been suggested, contrary to earlier schemes (Fowler et al., 1971), that the units catalysing the primary photochemical reactions (bacteriochlorophyll and associated redox components) are located in the cytoplasmic membrane (Olson et al., 1977; Boyce et al., 1977). The role of the chlorobium vesicle was suggested to be that of an antennae system, the light energy absorbed by the high concentration of chlorobium chlorophyll present in these structures being efficiently transferred to the primary site of energy transduction in the cytoplasmic membrane.

In the work presented here we have extended the range of inhibitors used to study the ATPase and photophosphorylation in vivo, measured the magnitude of the membrane potential $(\Delta \psi)$ component of the transmembrane proton electrochemical gradient $\left(\Delta \bar{\mu}_{\mathrm{H}^{+}}\right)$and measured the sensitivity of the process responsible for maintaining $\Delta \psi$ to a variety of inhibitors. Our results suggest that in the absence of light the cytoplasmic membrane is polarized due to the operation of the membrane-bound ATPase previously characterized. Under conditions of illumination the maintenance of $\Delta \psi$ was sensitive to both electrontransport inhibitors and ATPase inhibitors.

\section{METHODS}

Abbreviations. The following non-standard abbreviations are used: DCCD, $N, N^{\prime}$-dicyclohexylcarbodiimide: DICD, diisopropylcarbodiimide; CCCP, carbonyl cyanide $m$-chlorophenylhydrazone; DNP, 2,4-dinitrophenol; $\mathrm{DDA}^{+}$. dibenzyldimethylammonium; TPMP ${ }^{+}$, triphenylmethylphosphonium; chlorhexidene, 1,6-di-4-chlorophenyldiguanidohexane: $\mathrm{Nbf-Cl}$, 4-chloro-7-nitrobenzofurazan; DPPA, diphenylphosphorylazide; HOQNO, 2-heptyl-4-hydroxyquinoline- $N$-oxide.

Organism. The organism used was previously referred to as Chlorobium thiosulphatophylum (Burns \& Midgley, 1976) but is now referred to as Chlorobium limicola. It is strain 8346 of the NCIB.

Growth of organism. Acetate-supplemented medium was used as previously described (Burns \& Midgley, 1976). 
The preparation of washed bacterial suspensions, membrane-bound ATPase and the assay of ATPase activity (using Assay 1) and photophosphorylation in vivo were also described by Burns \& Midgley (1976).

Measurement of membrane potential. Values for $\Delta \psi$ were calculated from the concentration gradient of $\mathrm{Cs}^{+}$ using the Nernst equation in the following form:

$$
\Delta \psi=-2 \cdot 303 \frac{R T}{F} \log _{10}\left(\frac{\left[{ }^{137} \mathrm{Cs}^{+}\right]_{\text {in }}}{\left[^{137} \mathrm{Cs}^{+}\right]_{\text {out }}}\right)
$$

Valinomycin-dependent $\mathrm{Cs}^{+}$uptake was measured using a rapid filtration assay (Horan et al., 1978). Suspensions of organisms $\left(0.5 \mathrm{mg}\right.$ protein $\left.\mathrm{ml}^{-1}\right)$ were incubated in an atmosphere of $\mathrm{O}_{2}$-free $\mathrm{N}_{2}$ with or without illumination. The concentration of valinomycin was $2.5 \mu \mathrm{g}$ (mg protein) ${ }^{-1}$. The vessel used was constructed of glass and had four chambers maintained at $37^{\circ} \mathrm{C}$ by circulating water. Illumination was provided by four $60 \mathrm{~W}$ tungsten-filament bulbs, $1.5 \mathrm{~cm}$ from each chamber. Control experiments demonstrated that illumination in all four chambers was equivalent. Samples were removed at suitable intervals with a syringe through a Suba-seal cap and filtered through Oxoid membrane filters $(0.45 \mu \mathrm{m}$ pore size, $2.5 \mathrm{~cm}$ diam. $)$.

A value for the intracellular water of $2.5 \mu \mathrm{l}$ (mg protein $)^{-1}$ was measured using the method described by Stephenson et al. (1978).

Analyses. $\mathrm{P}_{\mathrm{i}}$, bacteriochlorophyll, protein and ATP were measured as previously described (Burns \& Midgley, 1976).

Chemicals. Inhibitors were obtained from the sources listed by Stephenson et al. (1978). Dio-9 was obtained from Gist-Brocades, Delft, Holland and DPPA from Aldrich Chemical Co.

\section{RESULTS AND DISCUSSION}

Inhibitor sensitivity of photophosphorylation in vivo. Burns \& Midgley (1976) showed that photophosphorylation in vivo was sensitive to the uncouplers CCCP and DNP, the energy-transfer inhibitors DCCD, DICD and phloridzin and the electron-transport inhibitor HOQNO. We have extended the range of inhibitors used in order that the processes involved might be more fully analysed (Table 1). The assay in vivo does not lend itself to a greater precision than classifying the degree of inhibition observed into the categories shown. Photophosphorylation was not affected by $\mathrm{NaCl}, \mathrm{MgCl}_{2}, \mathrm{CaCl}_{2}$ or $\mathrm{Na}_{2} \mathrm{SO}_{4}$ (all used at $30 \mathrm{~mm}$ ) or $\mathrm{NaBr}(4 \mathrm{~mm})$. In experiments similar to those previously described (Table 3 of Burns \& Midgley, 1976) the action of chlorhexidine was shown to be irreversible whereas the action of lipophilic cations was fully reversed by washing.

The inhibition observed with DPPA was notable since Burns \& Midgley (1976) showed that $\mathrm{N}_{3}{ }^{-}$was without effect on photophosphorylation although it was a potent inhibitor of ATPase activity in vitro. Our finding with regard to DPPA, which has been suggested to be more lipophilic than $\mathrm{N}_{3}^{-}$(Kin \& Anraku, 1974), indicated that this insensitivity was probably due to inaccessibility of $\mathrm{N}_{3}{ }^{-}$to the ATPase in the intact organism.

\section{Table 1. Inhibition of photophosphorylation in vivo by Chlorobium limicola}

These results were compiled from a series of experiments conducted as described by Burns \& Midgley (1976).

\begin{tabular}{|c|c|c|c|}
\hline \multirow[b]{2}{*}{ Compound } & \multicolumn{3}{|c|}{ Concentration $(\mathrm{mm})$ producing indicated degree of inhibition } \\
\hline & Total & Partial & None \\
\hline DPPA & $5 \cdot 0$ & 1.0 & $0 \cdot 1$ \\
\hline $\mathrm{Nbf}-\mathrm{Cl}$ & 0.1 & 0.05 & 0.005 \\
\hline TPMPBr & 4.0 & 1.0 & $0 \cdot 1$ \\
\hline $\mathrm{DDACl}$ & $4 \cdot 0$ & $1 \cdot 0$ & $0 \cdot 1$ \\
\hline $\mathrm{HgCl}_{2}$ & 0.2 & 0.05 & 0.001 \\
\hline Dio- 9 & $20^{*}$ & $10^{*}$ & $6^{*}$ \\
\hline Chlorhexidene & 0.22 & 0.11 & 0.055 \\
\hline
\end{tabular}


Table 2. Sensitivity of membrane-bound ATPase to energy-transfer inhibitors Glycerol-stabilized ATPase preparations were produced as described by Burns \& Midgley (1976). The
results were derived from a series of experiments in which the uninhibited controls had activities of
$3.3 \mu \mathrm{mol} \mathrm{min} \mathrm{min}^{-1}$ (mg protein) ${ }^{-1}$. Assays were initiated by adding the particulate preparation to the
complete assay mixture (including inhibitors) prewarmed for $5 \mathrm{~min}$. An assay period of 15 min was
used and the protein concentration in the assay was $0.2 \mathrm{mg} \mathrm{ml} \mathrm{m}^{-1}$.

\begin{tabular}{|c|c|c|}
\hline Compound & $\begin{array}{c}\text { Concentration } \\
(\mathrm{mM})\end{array}$ & $\begin{array}{c}\text { Inhibition } \\
(\%)\end{array}$ \\
\hline DPPA & $\begin{array}{l}1.0 \\
0.1 \\
0.01\end{array}$ & $\begin{array}{r}100 \\
60 \\
0\end{array}$ \\
\hline $\mathrm{Nbf}-\mathrm{Cl}$ & $\begin{array}{l}0.1 \\
0.05 \\
0.005\end{array}$ & $\begin{array}{r}100 \\
60 \\
0\end{array}$ \\
\hline Quercetin & $\begin{array}{l}1 \cdot 8 \\
0.3 \\
0.03\end{array}$ & $\begin{array}{r}100 \\
30 \\
0\end{array}$ \\
\hline Dio-9 & $\begin{array}{r}20^{*} \\
10^{*} \\
6^{*}\end{array}$ & $\begin{array}{r}100 \\
50 \\
0\end{array}$ \\
\hline Chlorhexidene & $\begin{array}{l}0.11 \\
0.033 \\
0.005\end{array}$ & $\begin{array}{r}100 \\
40 \\
0\end{array}$ \\
\hline
\end{tabular}

Inhibition of membrane-bound ATPase activity. A particulate preparation $\left(\mathrm{P}_{3}\right.$ of Burns \& Midgley, 1976) was made and the sensitivity of the ATPase to inhibitors of photophosphorylation in vivo was measured (Table 2). No inhibition was recorded using HOQNO, uncouplers or lipophilic cations. Inhibition by $\mathrm{Nbf}-\mathrm{Cl}$ or chlorhexidine was significantly increased if the particulate preparation was preincubated with these compounds; with quercetin or DPPA the degree of inhibition did not increase significantly (results not shown).

Thus there was a correlation between the sensitivity of the ATPase and the sensitivity of photophosphorylation in vivo to energy-transfer inhibitors. These results, together with those presented previously (Burns \& Midgley, 1976) are consistent with the operation of a light-driven electron-transport system coupled to ATP synthesis by means of a transmembrane $\Delta \bar{\mu}_{\mathrm{H}}$.

Measurement of the transmembrane $\Delta \bar{\mu}_{\mathrm{H}^{+}}$. In order to establish the role of the ATPase bound to the cytoplasmic membrane we have attempted to measure the magnitude of the $\Delta \bar{\mu}_{\mathrm{H}^{+}}$existing across the cytoplasmic membrane of the organisms under various conditions. We have been unable to measure the chemical potential component $(\Delta \mathrm{pH})$ of this gradient by following the distribution of weak acids such as 5,5'-dimethyloxazolidine-2,4-dione (Waddel \& Butler, 1959; Rottenberg, 1975) using either flow dialysis or a double-isotope filtration method. However, we have measured the $\Delta \psi$ component using bacterial suspensions buffered at $\mathrm{pH} 6.8$ when the contribution of the $\Delta \mathrm{pH}$ component to the overall $\Delta \bar{\mu}_{\mathrm{H}^{+}}$was probably small. As described in Methods, the $\Delta \psi$ component was measured using organisms made permeable to $\mathrm{Cs}^{+}$by means of valinomycin and measuring the accumulation ratio using a filtration technique. The value of the $\Delta \psi$ measured was independent of the valinomycin concentration in the range 2 to $30 \mu \mathrm{g}$ (ml bacterial suspension) ${ }^{-1}$ and independent of the $\mathrm{Cs}^{+}$ concentration in the range 0.05 to $0.4 \mathrm{~mm}$. When organisms were incubated in the dark a valinomycin-dependent $\mathrm{Cs}^{+}$uptake was observed that varied with different batches of the organism and $\Delta \psi$ fell in the range -65 to $-90 \mathrm{mV}$. In the dark the plateau in $\mathrm{Cs}^{+}$uptake occurred after $90 \mathrm{~min}$ (Fig. 1). The sensitivity of the process producing this $\Delta \psi$ was 


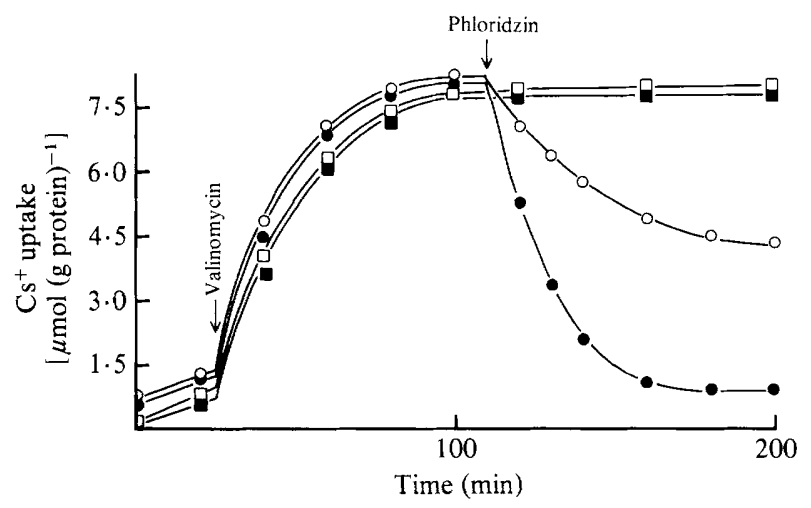

Fig. 1. Sensitivity to phloridzin of valinomycin-dependent uptake of $\mathrm{Cs}^{+}$by Chlorobium limicola incubated in the dark. The organisms were washed twice in morpholinopropane sulphonate buffer ( $40 \mathrm{~mm}$, adjusted to $\mathrm{pH} 6.8$ with Tris base) at $4{ }^{\circ} \mathrm{C}$. Bacterial suspension $(1 \mathrm{ml}$ ) was added to $4.7 \mathrm{ml}$ of similar buffer and $0.3 \mathrm{ml}{ }^{137} \mathrm{CsCl}\left[2 \mathrm{mM}, 2 \mu \mathrm{Ci} \mu \mathrm{mol}^{-1}\left(74 \mathrm{kBq} \mu \mathrm{mol}^{-1}\right)\right]$. Valinomycin $(7.5 \mu l$ of a $1 \mathrm{mg}$ $\mathrm{ml}^{-1}$ solution in methanol) was added after $25 \mathrm{~min}$. Phloridzin (dissolved in methanol) was added at the plateau of accumulation at the concentrations specified. $\mathrm{Cs}^{+}$uptake was assayed as described in Methods. $\square$, No addition; $, 0, \boldsymbol{\square},+$ phloridzin (10, 1 and $0 \cdot 1 \mathrm{mM}$, respectively).

\section{Table 3. Membrane depolarization induced by a variety of compounds in the dark}

These results were compiled from a series of experiments such as that described in Fig. 1.

\begin{tabular}{|c|c|c|c|}
\hline \multirow[b]{2}{*}{ Compound } & \multicolumn{3}{|c|}{ Concentration ( $\mathrm{mM}$ ) producing indicated degree of depolarization } \\
\hline & Total & Partial & None \\
\hline DCCD & $0 \cdot 3$ & $0 \cdot 1$ & 0.0025 \\
\hline DICD & 8 & $2 \cdot 4$ & 0.24 \\
\hline $\mathrm{NaN}_{3}$ & 30 & ND & ND \\
\hline $\mathrm{NaCl}$ & 30 & 10 & $4 \cdot 0$ \\
\hline DPPA & $5 \cdot 0$ & $1 \cdot 0$ & $0 \cdot 10$ \\
\hline Phloridzin & $10 \cdot 0$ & 1.0 & 0.10 \\
\hline $\mathrm{Nbf}-\mathrm{Cl}$ & 0.1 & 0.015 & 0.005 \\
\hline $\mathrm{CCCP}$ & 0.05 & 0.025 & 0.002 \\
\hline DNP & 4.0 & 1.0 & 0.25 \\
\hline TPMPBr & $4 \cdot 0$ & $1 \cdot 0$ & 0.10 \\
\hline $\mathrm{NaBr}$ & 30 & 10 & $4 \cdot 0$ \\
\hline $\mathrm{DDACl}$ & $4 \cdot 0$ & 1.0 & 0.1 \\
\hline $\mathrm{HgCl}_{2}$ & $0 \cdot 10$ & 0.025 & 0.001 \\
\hline Quercetin & 1.8 & 0.3 & 0.03 \\
\hline Dio-9 & $20^{*}$ & $10^{*}$ & $6^{*}$ \\
\hline
\end{tabular}

investigated by adding a variety of inhibitors. In initial experiments the $\Delta \psi$ was measured in the presence of DCCD $(0.3 \mathrm{mM})$, phloridzin $(10 \mathrm{mM}), \operatorname{CCCP}(50 \mu \mathrm{M}), \mathrm{TPMP}^{+}(4 \mathrm{mM})$ and $\mathrm{DDA}^{+}(4 \mathrm{mM})$ throughout the incubation period. All these compounds caused complete depolarization of the membrane. $\mathrm{NaN}_{3}(30 \mathrm{~mm})$ also depolarized the membrane; however, this was attributable not to $\mathrm{N}_{3}{ }^{-}$but to $\mathrm{Na}^{+}$, since similar effects were produced by $\mathrm{NaCl}$ and $\mathrm{NaBr}$. Experiments were then conducted in which $\mathrm{Cs}^{+}$accumulation was allowed to reach a plateau before the inhibitor was added, since such an approach also gave information on the rate of interaction of the inhibitor with the component responsible for generating the $\Delta \psi$ (Fig. 1). The results of such experiments are summarized in Table 3. 


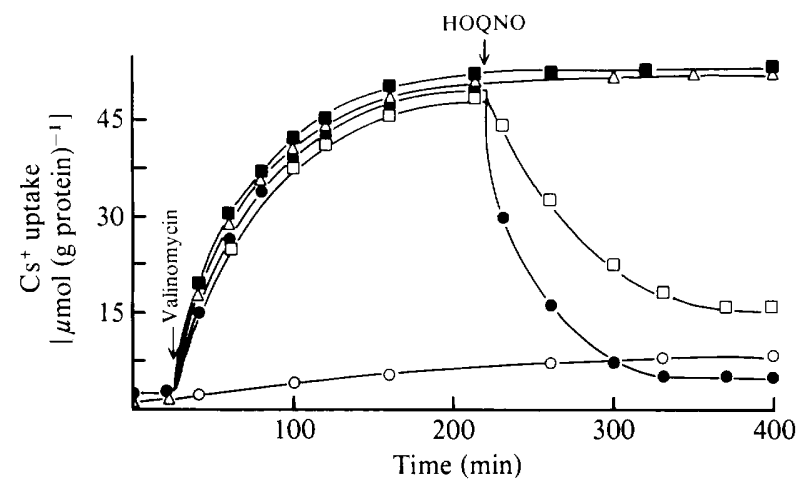

Fig. 2. Effect of 2-heptyl-4-hydroxyquinoline- $N$-oxide on valinomycin-dependent $\mathrm{Cs}^{+}$uptake by illuminated Chlorobium limicola. Bacterial suspensions were prepared as described in Fig. 1 and illuminated as described in Methods. Valinomycin $\left(7.5 \mu \mathrm{l}\right.$ of a $1 \mathrm{mg} \mathrm{ml}^{-1}$ solution in methanol) was added after $25 \mathrm{~min}$. HOQNO was added at the plateau of accumulation at the concentrations specified. $O$, No valinomycin; $\triangle$, + valinomycin, no HOQNO: $, \square, \mathbf{\square},+$ valinomycin + HOQNO $(40,20$ and $4 \mu \mathrm{M}$, respectively).

In the dark, depolarization of the membrane was not produced by HOQNO at concentrations causing inhibition of photophosphorylation in vivo. Depolarization was produced by $\mathrm{MgCl}_{2}, \mathrm{CaCl}_{2}$ or $\mathrm{Na}_{2} \mathrm{SO}_{4}$, all at $30 \mathrm{~mm}$. The magnitude of the $\Delta \psi$ when inhibitors were present was consistent with such a potential being maintained by an ATPase as indicated by the sensitivity to carbodiimides, phloridzin, DPPA, $\mathrm{Nbf}-\mathrm{Cl}$ and other inhibitors.

The magnitude of the $\Delta \psi$ was stimulated by illumination (Fig. 2), the degree of stimulation varying with different batches of organism. The range of values observed was -110 to $-155 \mathrm{mV}$, so that with a typical preparation the $\Delta \psi$ rose by a factor of approximately 1.7 on illumination. The process producing the $\Delta \psi$ was insensitive to $\mathrm{Na}^{+}$in the light but remained sensitive to ATPase inhibitors with unchanged concentration dependence.

In contrast to the observations made with suspensions incubated in the dark the process responsible for stimulating the formation of $\Delta \psi$ in the light was sensitive to HOQNO at concentrations similar to those inhibiting photophosphorylation in vivo (Fig. 2).

The possibility that the depolarization brought about by the energy-transfer inhibitors was a secondary rather than a primary effect has been considered. When DPPA, DICD, DCCD or phloridzin were added to suspensions of the organism incubated in the light, the membrane depolarization and the fall in the intracellular concentration of ATP had a similar time course (results not shown).

Our observations are consistent with the operation in the dark of a membrane-bound ATPase maintaining an appreciable $\Delta \psi$ across the cytoplasmic membrane, presumably to drive transport systems and maintain ion gradients under these conditions (Harold, 1974; Hamilton, 1976). In the light, however, the formation of a $\Delta \psi$ was stimulated and its maintenance became sensitive to HOQNO. The formation of $\Delta \psi$ in the light remained sensitive to energy-transfer inhibitors. This could indicate a direct role for the ATPase in maintaining this $\Delta \psi$ (i.e. by the hydrolysis of ATP generated at a site dependent on electron transport). An indirect role is also possible, for example, a structural or conformational role, such that if flux through the ATPase, in the direction of ATP synthesis, was inhibited then the maintenance of a $\Delta \psi$ might not be possible. At present we cannot distinguish between these possibilities but the suggestion that the primary photosystems are present in the cytoplasmic membrane (Olson et al., 1977; Boyce et al., 1977) makes it likely, in terms of the chemiosmotic hypothesis (Mitchell, 1968), that this is the coupling membrane. Further analysis of energy transduction in Chlorobium limicola would be greatly aided by the 
development of a system capable of catalysing photophosphorylation in vitro, but despite previous reports (Sykes \& Gibbon, 1967; Williams, 1957) we have been unable to produce preparations showing activities equivalent to those that we found with Rhodospirillum rubrum. The most active preparations that we have been able to produce, using a method based on that of Sykes et al. (1965), showed a rate of ATP production of $5 \mu \mathrm{mol} \mathrm{h}^{-1}(\mathrm{mg}$ bacteriochlorophyll) $)^{-1}$ (A. Sissons \& M. Midgley, unpublished observations).

A.S. acknowledges the award of an S.R.C. studentship. We thank Dr Y. Anraku for a sample of DPPA.

\section{REFERENCES}

Boyce, C. O. L., Oyewole, S. H. \& Fuller, R. C. (1977). Localization of photosynthetic reaction center in Chlorobium limicola. Brookhaven Symposia in Biology 28, 365 .

Burns, D. D. \& Midgley, M. (1976). Localization and possible role of an adenosine triphosphatase in Chlorobium thiosulphatophylum. European Journal of Biochemistry 67, 323-333.

Fowler, C. F., Nugent, N. A. \& Fuller, R. C. (1971). The isolation and characterization of a photochemically active complex from Chloropseudomonas ethylica. Proceedings of the National Academy of Sciences of the United States of America 68, 2278-2282.

Hamilton, W. A. (1976). Energy coupling in microbial transport. Advances in Microbial Physiology $12,1-53$.

HAROLD, F. M. (1974). Chemiosmotic interpretations of active transport in bacteria. Annals of the New York Academy of Sciences 227, 297-311.

Horan, N. J., Midgley, M. \& Dawes, E. A. (1978). Anaerobic transport of serine and 2-aminoisobutyric acid by Staphylococcus epidermidis. Journal of General Microbiology 109, 119-126.

KIN, E. \& AnRakU, Y. (1974). Diphenyl phosphorazidate: a new potent organic azide inhibiting energy transformation reactions. Journal of Biochemistry 76, 667-669.

Mitchell, P. M. (1968). Chemiosmotic Coupling and
Energy Transduction. Bodmin, Cornwall: Glynn Research Ltd.

Olson, J, M., Prince, R. C. \& Brune, D. C. (1977). Reaction center complexes from green bacteria. Brookhaven Symposia in Biology 28, 238-246.

RotTenberG, H. (1975). The measurement of transmembrane electrochemical proton gradients. Journal of Bioenergetics 7, 61-74.

Stephenson, M. C., Midgley, M. \& Dawes, E. A. (1978). Transport of $\alpha$-aminoisobutyrate by cells and membrane vesicles of Pseudomonas fluorescens. Biochimica et biophysica acta 509, 519-536.

Sykes, J. \& Gibron, J. A. (1967). ATP production in the light and the dark by vesicle preparations isolated from Chlorobium thiosulphatophilum L660. Biochimica et biophysica acta 143, 173-186.

Sykes, J., Gibbon, J. A. \& Hoare, D. S. (1965). The macromolecular organization of cell-free extracts of Chlorobium thiosulphatophilum L660. Biochimica et biophysica acta 109, 409-423.

W ADDEL, W. J. \& BUTLER, T. C. (1959). Calculation of intracellular $\mathrm{pH}$ from the distribution of 5,5dimethyl-2,4-oxazolidinedione (DMO). Application skeletal muscle of the dog. Journal of Clinical Investigation 38, 720-729.

Williams, A. M. (1957). Light-induced uptake of inorganic phosphate in cell-free extracts of obligately anaerobic photosynthetic bacteria. Biochimica et biophysica acta 19,570 . 